\title{
EL MUSEO COMARCAL, LA DIFUSIÓN DEL PATRIMONIO Y LA PLANIFICACIÓN TERRITORIAL DE LAS POLÍTICAS CULTURALES
}

La democracia cultural, es decir, el acceso de todos los ciudadanos a los bienes culturales, debe ser el principal objetivo de la política cultural: democracia cultural es sinónimo de descentralización de equipamientos y servicios.

A partir del concepto de democracia cultural definimos un modelo de equipamiento patrimonial básico: el museo comarcal, su concepción museológica, sus funciones y su forma de gestión. Proponemos a estos museos como centros generadores de la difusión del patrimonio en su ámbito territorial, nudos de una red provincial y puntos de conexión con otras políticas y actividades culturales.

\section{EL MARCO IDEOLÓGICO}

\section{Política cultural y territorio}

El territorio, en cuanto recurso complejo que integra población, medio físico, recursos naturales, capital fijo, medios financieros, cultura, etc., es el punto de partida de cualquier estrategia de desarrollo a medio y largo plazo.

El desarrollo sostenible de una región pasa por una valoración cultural del territorio que ponga de manifiesto la singularidad de sus recursos humanos y estimule la confianza de la comunidad en sí misma y en su capacidad creativa.

La política cultural debe ser planificada territorialmente si queremos que alcance al mayor número de habitantes y sea un elemento de equilibrio territorial. Esta planificación pasa por una clarificación del marco competencial de los diversos agentes implicados y la creación y descentralización de equipamientos y servicios. Una política cultural planificada es una política comprometida con el futuro.

La Administración Pública tiene que garantizar la distribución igualitaria de las infraestructuras y servicios que se consideren básicos, y avanzar hacia formas de cooperación entre los diferentes niveles de gobierno (Estado, Autonomías y Administración Local) que permitan hacer efectivos los proyectos de desarrollo sobre el territorio.
Los municipios son el ámbito natural del ejercicio de las políticas culturales. Al Estado y las Autonomías les corresponde legislar, planificar y gestionar los grandes espacios de capitalidad, pero la relación cotidiana e inmediata entre el ciudadano y la vida cultural se realiza en el municipio.

La principal misión de la administración cultural de las comunidades autónomas es la planificación territorial de las políticas culturales. Esto supone:

- Planificar, marcar objetivos e invertir en programas capaces de captar recursos de otras políticas más potentes (planes de desarrollo, empleo, turismo, etc.), en especial de la infraestructura educativa y de los medios de comunicación, para multiplicar su capacidad de acción y presencia en el territorio.

- Descentralizar la gestión cultural. Partir del hecho que para que el patrimonio pueda ser usado como recurso eficaz para el desarrollo socioeconómico, debe ser entendido y gestionado desde el territorio o comarca, como una globalidad: museos, archivos, bibliotecas, conjuntos históricos, monumentos, etc.

- Coordinar a los agentes culturales, públicos y privados, que actúan sobre el territorio, en particular a las diputaciones y a los municipios.

\section{Equipamientos e infraestructuras culturales}

Una política de equipamientos es imprescindible para el desarrollo cultural. Independientemente de la "vocación cultural" de cada opción política y de las particularidades de cada administración, parece claro que determinadas infraestructuras culturales deberían afrontarse y planificarse como equipamientos básicos de carácter general, configurándose un modelo cultural para toda una comunidad autónoma.

Organismos de la administración autónoma, diputaciones y ayuntamientos, tienen la responsabilidad de definir sus respectivos marcos competenciales con el objeto de armonizar la acción cultural, clarificar los ámbitos de actuación públicos y privados, concretar planes de equipamientos básicos, mode- 
los de financiación, etc. Sin una clarificación del marco competencial de las distintas administraciones difícilmente podrá programarse una acción cultural razonable sobre el territorio.

Para la financiación de las infraestructuras culturales hay que lograr un acuerdo cultural, con un compromiso de las distintas administraciones en las cuotas de participación económica para cada tipo de servicio. El siempre escaso presupuesto público de las distintas administraciones para la cultura debe ser prioritariamente empleado en la financiación de infraestructuras y su funcionamiento. Por contra, las acciones culturales puntuales y emblemáticas son el campo natural de acción de la iniciativa privada y el mecenazgo!.

\section{El patrimonio: \\ un sector básico de la política cultural}

El patrimonio es a la vez un objetivo y una herramienta o recurso al servicio del diseño de la política cultural. El concepto integral del patrimonio tiene como dimensión la globalidad del territorio y sus habitantes. Su finalidad última es la calidad de vida consecuencia del desarrollo económico y social sostenible. Su metodología es la gestión integral a partir de estrategias territoriales.

El patrimonio puede ser una fuente de identidad, cohesión social y participación ciudadana, que debe ser entendido como un servicio a la población, necesario de gestionar:

- Hay que buscar fórmulas descentralizadas de gestión que garanticen la autonomía, la responsabilidad, la iniciativa, la innovación y la diversificación de las fuentes de ingresos, tanto públicos como privados.

- Hay que fomentar experiencias más democráticas de gestión pública del patrimonio, mediante la creación de estructuras abiertas a la participación activa de usuarios y asociaciones.

- Hay que desarrollar fórmulas de gestión que permitan evaluar los resultados y faciliten el aumento de la productividad.
Este concepto de gestión, entendida como la interacción de formas diversas de demanda y de ofertas, de agentes públicos y privados que intervienen, y de acciones a desarrollar sobre un mismo territorio, implica:

- Un alto nivel de planificación.

- El desarrollo de una cultura proyectual en relación con el patrimonio.

- La creación de instrumentos más adecuados a estas nuevas finalidades.

- La formación de profesionales capaces de llevar a cabo esta nueva gestión del patrimonio².

\section{La difusión del patrimonio: una política cultural desestructurada}

Es comúnmente aceptado, y así lo recogen la legislación nacional y las recomendaciones internacionales, que la investigación y conservación del patrimonio no tiene sentido sin su difusión ${ }^{3}$.

Este principio general, que aparece en los preámbulos de las leyes de patrimonio, no tiene posteriormente un desarrollo normativo. Conceptos tales como difusión, democracia cultural o equilibrio territorial, no pasan de ser una mera declaración de intenciones.

\section{A partir del concepto de democracia cultural definimos un modelo de equipamiento patrimonial básico: el museo comarcal, su concepción muse- ológica, sus funciones y su forma de gestión. Proponemos a estos museos como centros generadores de la difusión del patrimonio en su ámbito territorial, nudos de una red provincial y puntos de conexión con otras políticas y actividades culturales.}

Tradicionalmente la legislación de patrimonio se ha orientada a la conservación de los objetos. A ello se destinan títulos completos de la ley, cuya aplicación ha generado instrumentos de protección y una estructura administrativa para su aplicación. Al mismo tiempo los "profesionales del patrimonio" (arquitectos, restauradores, arqueólogos, historiadores del arte, archiveros, conservadores de museo, etc.), presentan un perfil formativo clara- 
mente enfocado al ámbito de la investigación o la conservación.

Por contra, la política cultural, tal como la entendemos hoy día, está orientada a las personas y a su enriquecimiento mediante la difusión cultura. La difusión del patrimonio no tiene desarrollo legal ni perfiles profesionales claros; se han generado escasos instrumentos para su ejecución y su estructura operativa es liviana y desestructurada.

Sobre el territorio están actuando diversas administraciones públicas en temas relacionados con la difusión y promoción del patrimonio (diversas consejerías de los gobiernos autónomos, diputaciones y municipios), en una acción de carácter voluntarista: todos ellos pueden ejercer la difusión del patrimonio, pero no hay ninguna normativa legal que obligue a actuar en ese sentido, ni que exija equipamientos básicos para esta misión.

La difusión es una "gestión cultural mediadora entre el patrimonio y la sociedad" y por tanto una acción permanente que necesita de profesionales y de equipamientos ${ }^{4}$. Hay que adaptar la difusión del patrimonio a las distintas necesidades territoriales con acciones más profesionales, más organizadas y estables, mediante propuestas de creación y descentralización de equipamientos, racionalización de las inversiones, formación profesional y evaluación de los proyectos.

\section{UN MODELO DE EQUIPAMIENTO BÁSICO PARA LA DIFUSIÓN DEL PATRIMONIO: EL MUSEO COMARCAL}

A continuación presentamos un modelo de museo con objetivos territoriales, de gestión ágil y vocación social, "corazones" estratégicamente situados, que den servicio a un grupo de municipios y a su vez sean nudos de una red y puntos de referencia de otras políticas: educativa, turística, medioambiental, etc.

Pretendemos que este equipamiento básico o dotación mínima para la difusión y promoción del patrimonio en el ámbito comarcal, sirva de modelo de referencia a cualquiera de los posibles entes promotores que deseen ponerlo en funcionamiento: organismos públicos (municipios, mancomunidades, diputaciones, diversas Consejerías); iniciativa privada (asociaciones, fundaciones) o entes mixtos.

\section{Un museo de acción integral}

Las numerosas experiencias realizadas en distintos países, que tras la $2^{a}$ Guerra Mundial intentaron cambiar la imagen monolítica de los museos, tomaron cuerpo teórico en la llamada Mesa Redonda de Santiago de Chile, organizada por la UNESCO en 1972. Allí nació el concepto de "Museo Integral", con un definitivo carácter social:

"El museo es una institución al servicio de la sociedad a la que pertenece y posee en sí mismo los elementos que le permiten participar en el proceso de formación de la conciencia de la comunidad a la que sirve"5.

En esta misma línea se desarrollaron los museos vecinales de las "Inner Cities" estadounidenses, y los museos locales y de barrio existentes en Centro y Sudamérica. Pero quizá fueron los museólogos franceses (G.H Riviere, H. Varinne Bohan y M. Evrard, entre otros) los que más ahondaron conceptualmente en los presupuestos del museo integral, creando el cuerpo teórico de lo que se denominó el ecomuseo 6 .

El objeto último que persigue el museo integral, ecomuseo, museo comunitario, museo de identidad, etc., es contribuir al desarrollo de la comunidad en la que está ubicado. En este sentido el museo debe dedicarse a la interpretación del presente y su transformación, más que a la exaltación del pasado: museos destinados a crear la conciencia de patrimonio, más centrados en las personas que en los objetos, instituciones que sirvan a las necesidades de un grupo social y su desarrollo.

Un concepto integral del museo implica que sus responsables pongan al servicio del desarrollo social el patrimonio y la memoria colectiva. Su programa museológico no debe basarse en los objetos que posee o querría poseer, sino en las ideas que quiere transmitir. En vez de un museo "de", un museo "para" y en función de una comunidad?.

Museos del tiempo y del espacio, su principal campo de investigación es la historia de un hábitat, es decir, la relación dialéctica existente entre una población y el espacio que ocupa, de donde nace el sentido de la identidad.

Un centro transmisor de cultura, integrado en la comunidad, que garantice la continuidad y la creación de nuevos hábitos culturales. 
Un museo que genere comunicación e intensifique la vida social, que busque la participación ciudadana y movilice a una parte considerable de la población en su diseño, planificación, ejecución y evaluación.

Cuando estos museos aborden el fenómeno turístico, ofrecerán a sus visitantes experiencias originales de inserción en su territorio, pero no separarán el desarrollo turístico del desarrollo global del medio, y no dejarán únicamente en manos de los agentes turísticos la tarea de crear el sistema de atracciones. En resumen, un museo abierto, participativo, esencialmente educativo y dinámico, con las siguientes características:

- Que ofrezca, a la comunidad que lo ha creado, elementos que le permitan reconocerse a través de las manifestaciones de su cultura.

- Que profundice en el estudio de los elementos que componen la realidad y raíces del territorio.

- Que, partiendo del presente, trabaje para la reconstrucción del pasado y se proyecte hacia el futuro, enriqueciéndose con los aportes de la historia y la vida cotidiana.

- Que considere como objeto de su atención el patrimonio comunitario, en su más amplia acepción; que incluya no sólo las manifestaciones físicas y espirituales del pasado, sino también las vivencias, las tradiciones orales, la música, la danza, el arte popular y todas las manifestaciones creativas del presente.

- Que permanentemente tienda a la valoración, la conservación y la difusión del patrimonio cultural del territorio y que dinámicamente satisfaga las necesidades de información y ocio de la comunidad.

- Que asuma la condición de institución cultural activa, protagonista en el proceso de desarrollo cultural del territorio y promotora de la dimensión cultural del desarrollo global.

- Que se arrogue el derecho de ser instrumento de cambio y de acción comunitaria; que requiera, aspire y exija conocer las necesidades de la comunidad a la cual pertenece.

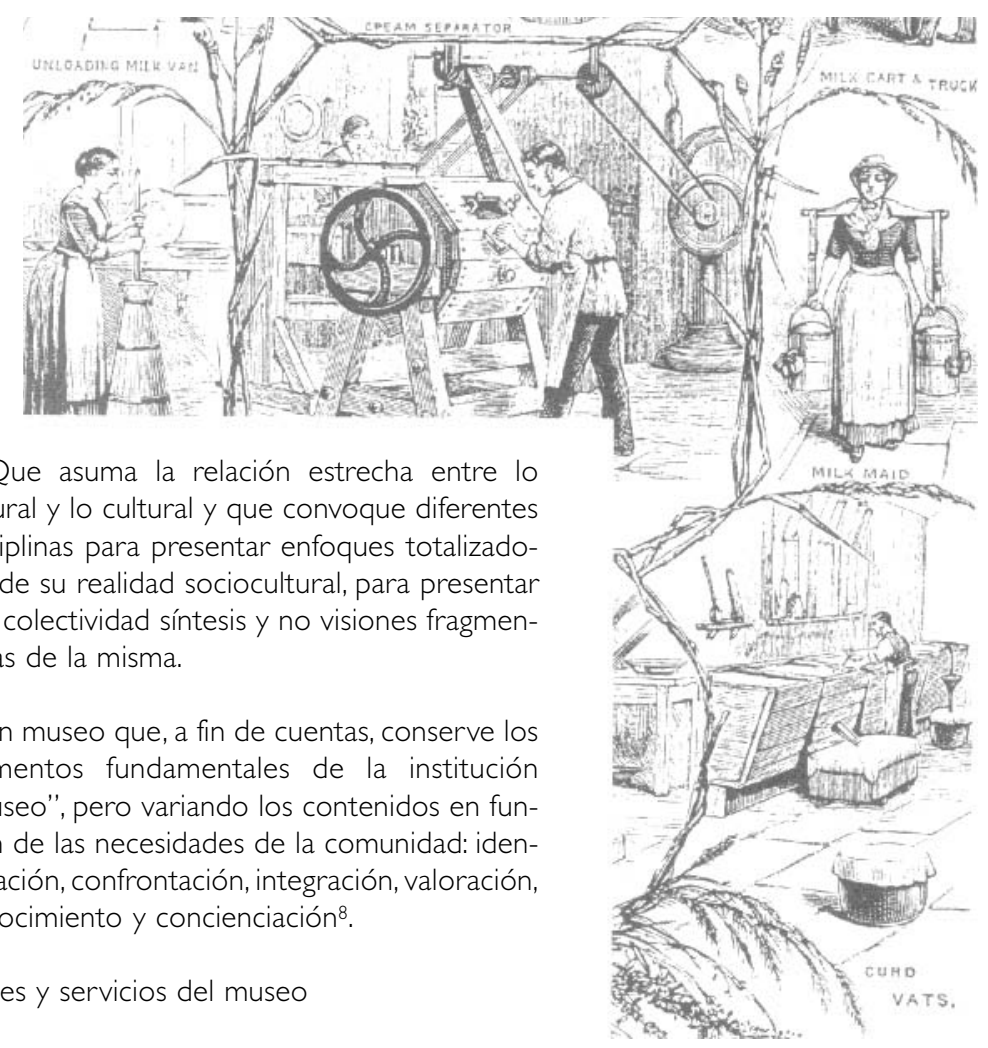

En museos comarcales, mayoritariamente instalados en el ámbito rural, más que visitantes hay que aspirar a crear usuarios, por lo que la oferta tiene que ir mucho más allá de mantener una colección expuesta y realizar otras actividades de investigación, catalogación, conservación, etc. De lo que estamos hablando es de maquinarias de dinamización social y cultural.

Aparte de las funciones que la legislación contempla como necesarias de realizar por una institución de estas características, aquí añadiremos otras que consideramos fundamentales para el desarrollo de un museo comarcal?.

\section{En el ámbito del patrimonio:}

- Instalar una exposición permanente. Para ello investigar, adquirir, conservar y exponer todo tipo de objetos representativos del patrimonio y la cultura de su territorio.

- Diseñar un plan de interpretación y presentación, que desarrolle de forma sistemática los contenidos del mensaje que se quiere transmitir al público, los sistemas de difusión, los servicios de atención al público y los servicios complementarios.

- Concretar un plan de conservación preventiva de adecuación del museo al mantenimiento de sus colecciones.

- Promover la investigación sobre el territorio de los especialistas del patrimonio y fomentar la investigación participativa de los habitantes. 
- Profundizar en el conocimiento de los recursos culturales y naturales de la zona, elaborando su inventario.

- Coordinarse con la política de protección del patrimonio de las consejerías de cultura en su ámbito territorial.

- Conectarse a los circuitos culturales y expositivos de las diputaciones, consejerías de cultura, cajas de ahorro, etc.

- Organizar exposiciones temporales concebidas para reforzar el sentimiento de autoestima y de dignidad de la población de su ámbito territorial.

- Organizar exposiciones itinerantes para que circulen por los distintos municipios de su comarca y para el intercambio con otras comarcas.

- Mantener relaciones permanentes con otros museos, archivos y bibliotecas de la comarca, colaborando en proyectos conjuntos.

\section{En el ámbito educativo:}

- Colaborar estrechamente con la red educativa de su territorio, poniendo el museo al servicio de la labor pedagógica de los profesores de colegios, institutos y centros de adultos.

- Confeccionar material docente o participar activamente con los profesores en su elaboración, para que la asignatura que la LOGSE contempla como de conocimiento del medio se imparta a partir de ejemplos del ámbito comarcal, y así refuerce la identidad y sensibilice y responsabilice al alumnado en la conservación y transmisión del patrimonio.

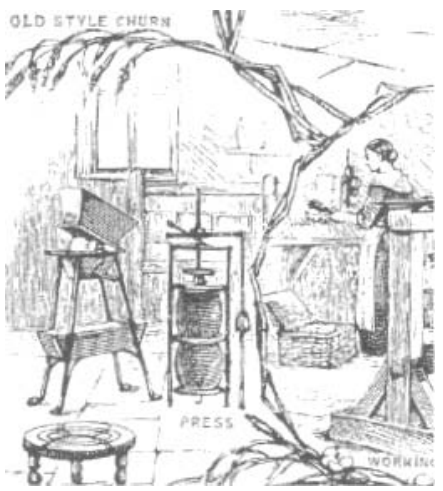

\section{En el ámbito sociocultural:}

- Colaborar con la política de creación y promoción artísticas, integrándose en el conjunto de la dinámica cultural, y ser un elemento fundamental para la vertebración de las políticas culturales de la comarca.

- Relacionarse con las casas de la cultura y los programas de animación sociocultural.

- Facilitar las instalaciones del museo para que la comunidad organice los programas y celebraciones que den vida al museo o que contribuyan a definir y difundir las realidades sociales, culturales y económicas de la comarca.

- Estar en permanente contacto con el tejido asociativo de la comarca: asociaciones culturales, musicales, de vecinos, de mujeres, juveniles, etc., o cualquier grupo de creación e innovación.

- Conectar con la política juvenil y sus servicios de información.

- Participar y promover iniciativas de desarrollo local y comarcal como Escuelas Taller, programas LEADER o cualquier otra iniciativa de desarrollo en su territorio.

\section{En el ámbito turístico:}

- Mantener estrechas relaciones con las oficinas de turismo, hoteles y, en general, con la política e infraestructura turística de la comarca.

- Poner el museo a disposición del turismo, facilitando la asimilación y comprensión de la cultura local, haciendo de una experiencia de ocio un aprendizaje cultural.

- Colaborar con los guías turísticos, apoyándolos en su labor de difusión cultural, para que ésta sea científica y ajustada a la realidad.

\section{En el ámbito del medioambiente:}

- Poner el museo al servicio de la educación ambiental, en cualquiera de sus facetas, apoyando en todo momento el concepto de desarrollo sostenible.

- Colaborar con las asociaciones de defensa del medio ambiente.

- En aquellas comarcas que sean Parque Natural, conectar con la red de Puntos de Información y Centros de Visitantes, participando activamente en su política de difusión y promoción, y apoyar su labor de turismo rural.

\section{En el ámbito de los medios de comunicación:}

- Estar siempre dispuesto a colaborar con los medios de comunicación, sobre todo en aquellos de ámbito comarcal, e introducir continuamente el mensaje patrimonial. 
- Promover, junto con los profesionales de la comunicación, proyectos de difusión del patrimonio en prensa radio y televisión.

\section{Público destinatario}

Cada comarca debe hacer un estudio detallado del público y usuarios del museo en su ámbito territorial. Este estudio comprendería al menos dos bloques:

- Público usuario residente en la comarca: adultos fuera de la edad escolar, en sus diversas categorías, estatus sociales, edades, niveles de instrucción etc., y personas en período de formación (Preescolar, E.G.B., B.U.P., F.P., formación de adultos, etc.).

- Público visitante: turismo de un día de excursión, de fin de semana, de veraneo; por viaje de negocios, placer, estudio, visitas a familiares y amigos, etc.; de procedencia provincial, regional, nacional, europea y otros países extranjeros.

Cada museo comarcal debe elaborar un plan de marketing dirigido a conocer y satisfacer la demanda de los diferentes segmentos de su público usuario, que le permita desarrollar una tarea sistemática y continuada de relaciones públicas, publicidad, y promoción.

\section{Recursos humanos, perfil de la plantilla y for- mación}

Hoy en día, la riqueza de un museo reside en su potencial de información y comunicación, en su capacidad técnica, en su personal especializado, en su programa museológico y en su integración en el entorno territorial y social.

Una parte fundamental del éxito de una institución como la que hemos definido estriba en:

- Que el personal esté motivado y vinculado con la comarca, y que crea en el papel fundamental que la cultura desempeña en el desarrollo comarcal.

- Que el equipo de dirección esté formado en la planificación y la gestión cultural.

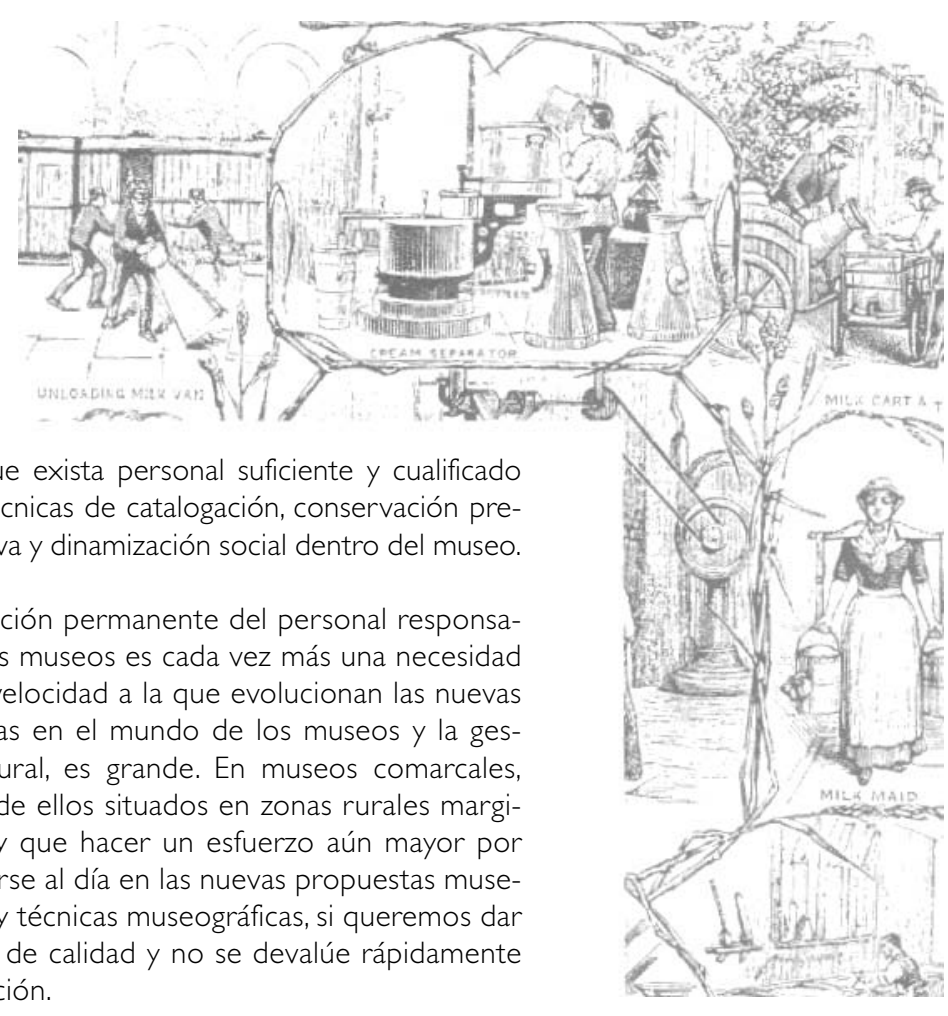

La formación permanente del personal responsable de los museos es cada vez más una necesidad vital. La velocidad a la que evolucionan las nuevas tendencias en el mundo de los museos y la gestión cultural, es grande. En museos comarcales, muchos de ellos situados en zonas rurales marginales, hay que hacer un esfuerzo aún mayor por mantenerse al día en las nuevas propuestas museológicas y técnicas museográficas, si queremos dar servicios de calidad y no se devalúe rápidamente la institución.

\section{Modelo de gestión}

\section{Régimen jurídico:}

La figura legal que pretendemos para estos museos puede ser la de un consorcio donde participen directamente tres instituciones públicas básicas:

- Los ayuntamientos de la comarca donde reside el museo comarcal, por ser beneficiarios directos del equipamiento y tener competencia en cultura.

- La administración de cultura de los gobiernos autónomos, por ser el principal organismo competente en materia de patrimonio y cultura.

- Las diputaciones que, por tradición y poder económico, siguen desarrollando actividades en patrimonio y promoción cultural.

Dependiendo del lugar donde se ubique el museo pueden también participar otras administraciones autónomas (medio ambiente, agricultura, turismo educación, etc.), mancomunidades, cajas de ahorro, fundaciones, asociaciones, empresas, etc.

La debilidad de un modelo de gestión donde participan múltiples instituciones, radica en lo difícil que es poner de acuerdo en proyectos comunes $y$ de manera continuada a responsables de distintas administraciones, más aún si pertenecen a partido políticos enfrentados.

Estructura organizativa: 
- Un consejo de dirección con representantes de los distintos entes promotores. Designan al director del museo y toman las grandes decisiones financieras y políticas de la institución.

- Un comité científico, presidido por el director y formado por el personal técnico que trabaja en el museo. Tiene como principal misión la programación y evaluación anual de las actividades.

- Un comité de usuarios, que participa activamente en la programación de las actividades relacionadas con el público y en los temas relativos al voluntariado y la participación ciudadana en el museo. Algún representante del comité de usuarios está presente en el comité científico y en el consejo de dirección.

Sería óptimo que la gestión de estas instituciones corriera a cargo de alguna asociación, fundación, u otra entidad sin ánimo de lucro, vinculada a la comunidad, que coordinara las relaciones entre el consejo de dirección, el comité científico y el comité de usuarios.

1. FERNÁNDEZ PRADO, E. La política cultural: que es y para que sirve. Gijón 1991. MARCE $X$. Algunas Reflexiones sobre la situación actual de las políticas culturales en Catalunya. Políticas Culturales. Dossier $n^{\circ} 2$ del Diploma de Postgrado en Gestión y Políticas Culturales de la Universidad de Barcelona, cur so 94/95.VILA. F; PICAS, O. Cultiva i territorio possibilitats, limitacions, reptes. Intereració 94. Barcelona 1995.

2. PARDO, J. Patrimonio Cultural. El sector cultural en España ante el proceso de integración europea. Madrid 1992, pp. 246 283. PARDO, J. El Patrimoni cul tural en el contex de les polítiques culturals. Interacció 94. Barcelona 1995.

3. Ver el preámbulo de la Ley 16/1985, de 25 de junio, del Patrimonio Histórico Español y de otras legislaciones de las comunidades autónomas, como la Ley 1/1991, de 3 de julio, de Patrimonio Histórico de Andalucía.

Cada museo comarcal debe dotarse de un instrumento de planificación estratégica, es decir, la identificación de potencialidades, la definición de los objetivos prioritarios, señalar el papel de los diferentes agentes que pueden intervenir, e implementar una estrategia de gestión para alcanzar los obje-

Además de lo ya expuesto en el apartado de funciones y servicios sobre la rentabilidad cultural y social de estos museos, el plan estratégico incluiría a su vez dos planes específicos:

- Un plan de gestión que defina las fórmulas organizativas más adecuadas, los recursos humanos y materiales, los procesos de producción, etc.

- Un plan de financiación que defina las necesidades presupuestarias, e identifique los diversos canales de financiación a partir de aportaciones públicas, de patrocinio del sector privado; de donaciones, de explotación de servicios, concesiones, etc.
El objetivo es desarrollar estrategias de gestión basadas en la planificación, dirigidas a hacer una política de patrimonio más eficaz con los recursos que tengamos, reduciendo costes y maximizando los beneficios.

Una fórmula a poner en marcha a partir de la existencia de una red de museos comarcales, es la gestión mancomunada de servicios especializados entre diversos centros y otras instituciones del patrimonio.

\section{Financiación y gestión económica:}

Dadas las características socio-económicas y administrativas actuales de la mayor parte del territorio español, el grueso de la financiación de los equipamientos culturales básicos ha de ser pública y diversificada.

Dependiendo del número de organismos públicos que participen en el consorcio creado para el museo (municipios, diputaciones, consejerías, etc.), más variadas serán las fuentes de financiación. Diversificar la financiación fortalece al proyecto por un lado, dado que no depende de los avatares de una sola administración, pero por el otro exige un gran esfuerzo de gestión financiera, que se complica cuantas más fuentes de ingreso en pequeñas partidas haya. tivos propuestos.
Una parte importante de la financiación de proyectos patrimoniales puede proceder de los Fondos Estructurales y de los Programas Comunitarios, como son: Escuelas Taller, programas LEADER, sobre todo en aquellas regiones europeas consideradas como Objetivo I, es decir, casi toda España.

No es habitual la participación privada en la financiación de equipamientos de las características aquí expuestas. También vemos difícil que la ganancia producto de la venta de entradas o compras en la tienda del museo, pueda ser significativa. Esto no quita para que se ensayen el mayor número de vías posible de financiación y se actúe con una mentalidad de rentabilización y amortización de las inversiones.

Hay que introducir el análisis económico y las nuevas técnicas de gestión y conseguir en los museos comarcales su máxima rentabilidad cultural, socioeconómica y financiera. 


\section{Evaluación estratégica:}

Los museos comarcales deben generar mecanismos de evaluación que les permita valorar la adecuación de los resultados con los objetivos previstos y determinar la efectividad de su acción respecto a la comunidad. Hay que definir para este tipo de instituciones los indicadores que muestren los coeficientes de eficiencia y eficacia alcanzados en todas sus vertientes.

\section{Los museos provinciales y la red de museos comarcales}

Los museos provinciales deben ser las cabeceras de la red de museos comarcales, es decir, equipamientos de capitalidad que ofrecen el apoyo técnico y los servicios que, por su carácter especializado o su alto costo económico, no se justificarían en cada ámbito comarcal. Para ello tendrían que:

- Animar la cooperación entre los diferentes museos, en especial el terreno de la difusión, ofreciendo apoyo técnico, elaborando proyectos conjuntos y organizando circuitos provinciales de exposiciones.

- Procurar evitar la duplicación de esfuerzos, racionalizando la política de adquisiciones, animando a compartir personal técnico y otros servicios especializados.

- Dar asistencia técnica en todo lo relacionado con el patrimonio y la escuela, mediante sus gabinetes pedagógicos.

- Asesorar en materia de presentación y planes de interpretación.

- Diseñar, con el personal de los museos comarcales, los planes de conservación preventiva y ofrecer asesoramiento continuo.

- Unificar los criterios de catalogación y registro de las colecciones.

- Ofrecer un servicio de talleres de restauración.

- Ofrecer un servicio de préstamos bibliotecarios de publicaciones especializadas.

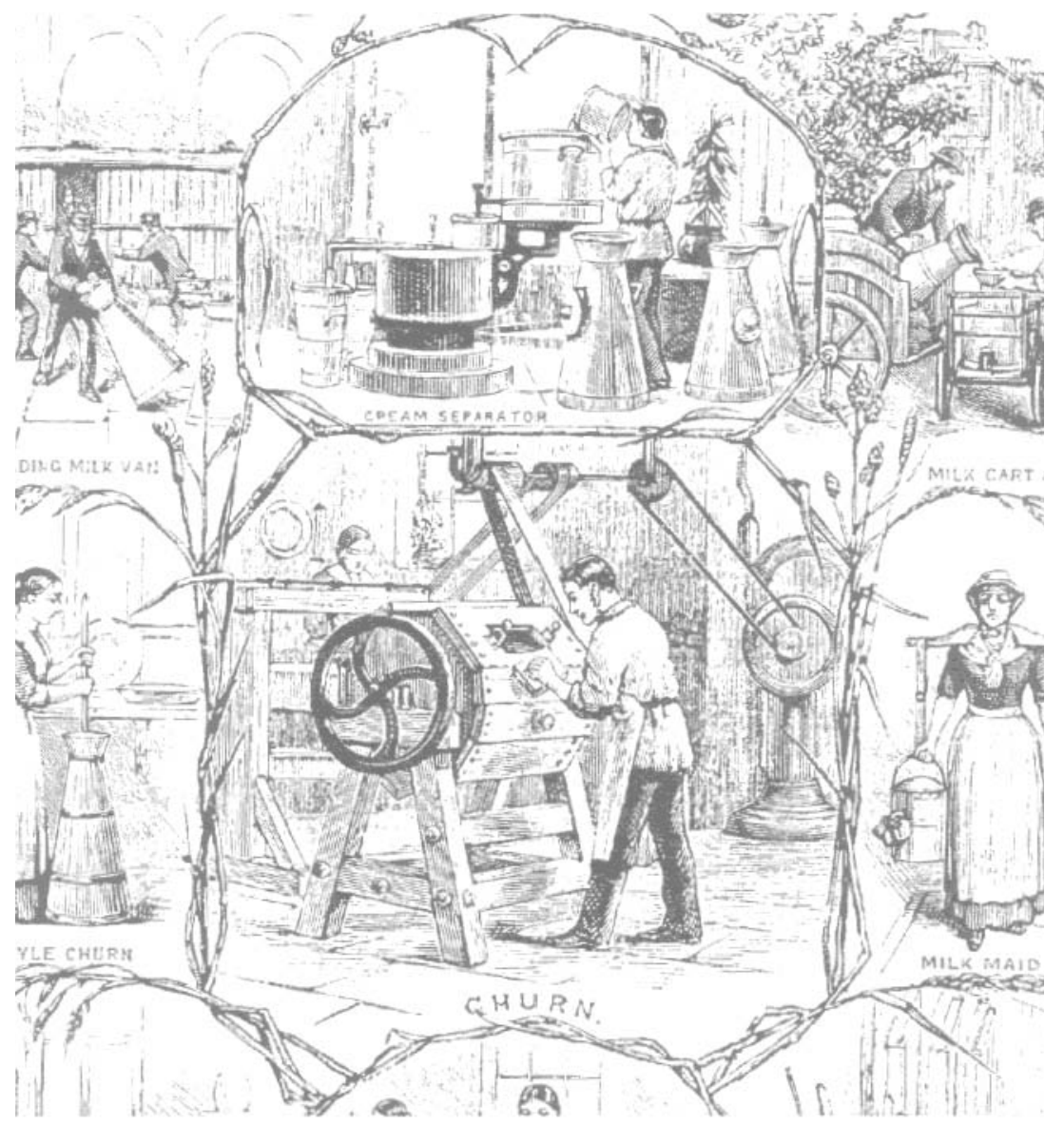

- Asesoramiento en los planes de gestión y marketing de los museos.

- Formación del personal en todas las áreas del patrimonio y los museos, y en concreto, en temas relacionados con la gestión del patrimonio en el ámbito comarcal.

\section{CONCLUSIONES}

A partir de objetivos comunes y del estudio detallado de sus características territoriales, cada comarca debe diseñar un museo a la medida de sus necesidades y posibilidades. En algún caso no se tratará tanto de crear nuevos equipamientos como de potenciar o redefinir los ya existentes.

No defendemos que la administración cultural de las comunidades autónomas cree y sostenga bajo su presupuesto y titularidad una red de museos distribuidos por todo el territorio. Las consejerías de cultura deben marcar objetivos, planificar, promover, coordinar y asesorar técnicamente a los museos comarcales, y sostener económicamente los equipamientos de capitalidad. La iniciativa de la creación de estos museos debe de partir del consenso político y social sobre unos principios mínimos de política cultural en el ámbito comarcal, por supuesto, con el apoyo económico, pero no exclusivo, del organismo responsable de la cultura en el gobierno autónomo. vo del Instituto Andaluz del Patrimonio Histórico $n^{\circ} \quad 5$, diciembre de 1993, pp. 6-7. MARTÍN, M. La Difusión del Patrimonio Il. Boletín Informativo del Instituto Andaluz del Patrimonio Histórico $n^{\circ} 6$, marzo de 1994, pp. 34-37.

5. Museum 25 (3) 1973.

6. Museum 148, 1985. RIVIERE, G.H. La Museología. Madrid 1993.

7. SOLA, T. Concepto y naturaleza de la museología. Museum 153, 1987, pp. 45-49.

8. Estos objetivos son del artículo de GOMEZ DE BLAVIA, M. El Museo de Barquisimeto: "inventar o errar". Museum 148, 1985 , pp. 224-229.

9. Las funciones tradicionales de un museo son las que se recogen en la legislación de patrimonio: "adquirir, conservar, investigar y exhibir", y que se desarrollan en legislaciones más específicas, como en el caso de la Ley 2/1984, de enero, de Museos Andaluces, de la Comunidad Autónoma de Andalucía. 